\title{
Election 44: What are the federal parties promising on health?
}

- Cite as: CMAJ 2021 September 20;193:E1472-4. doi: 10.1503/cmaj.1095962

Posted on cmajnews.com on September 7, 2021

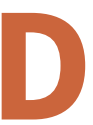
ebate over vaccine mandates kicked off the federal election campaign. But the major parties' platforms largely look toward postpandemic recovery - from tackling surgical backlogs and health worker shortages to shoring up medical stockpiles and mental health supports.

\section{Curbing COVID-19}

Prime Minister Justin Trudeau called the early election two days after announcing that his government would require federal public servants and travellers on planes, trains and cruise ships to be vaccinated against COVID-19. To support the plan, the Liberals would launch a \$1-billion fund for provinces and territories implementing proof of vaccination systems and table legislation to protect businesses that implement their own mandates.

In other measures to curb the spread of SARS-CoV-2, a re-elected Liberal government would introduce 10 days of paid sick leave for federally regulated workers, ensure free access to COVID-19 booster shots, and invest some $\$ 180$ million in ventilation projects, including in schools and Indigenous communities. The Liberals would also create a refundable tax credit so small businesses can claim up to $\$ 50000$ in eligible ventilation improvement expenses.

Like Trudeau, New Democratic Party Leader Jagmeet Singh supports vaccine mandates for travellers and federal workers. He called for workers who break the rules to face progressive discipline including firing.

Both the Liberals and the NDP required their candidates to be vaccinated before they hit the campaign trail. The Conservatives and Green Party did not.

Conservative Leader Erin O'Toole is proposing to require unvaccinated travellers and federal workers to take COVID-19 tests as part of a national rapid screening program.

The Conservatives would also screen everyone entering Canada for COVID-19 regardless of vaccination status, speed up approvals of rapid tests deployed by peer nations, make available at-home tests, and immediately provide more rapid test kits to provincial governments to conduct screening in schools. At the same time, a Conservative government would develop benchmarks for lifting pandemic restrictions.

Like the Conservatives, the Bloc Québécois wants COVID-19 testing at the border. The Bloc would also establish a mechanism for verifying proof of vaccination and campaign for the lifting of vaccine patent protections.

Green Party Leader Annamie Paul sidestepped questions from reporters about mandatory vaccination but said she is interested in "knowing the details" of the Liberals' plan. The party has yet to unveil its full platform, stating it will be released day-byday until the election.

\section{Access to care}

Improving access to care remains a major pillar of the Liberals' health platform. They are committing to immediately invest $\$ 6$ billion to help eliminate health system waitlists on top of $\$ 4$ billion already promised in budget 2021 .

Over the next four years, the Liberals would invest $\$ 3.2$ billion to hire 7500 new family doctors, nurse practitioners and nurses, as well as $\$ 400$ million to expand virtual health care services.

To address health worker shortages outside major cities, the Liberals would increase debt relief for rural health care professionals and social service providers from $\$ 40000$ up to $\$ 60000$ over five years and expand eligibility to include dentists, pharmacists, social workers, psychologists, teachers, and others. They would also offer health care professionals a one-time tax deduction of up to $\$ 15000$ over their first three years of practice in a rural or remote region.

The Liberals' platform lists "moving forward" on universal pharmacare among the party's accomplishments but contains no new promises to that end.

By contrast, the NDP is committing $\$ 10$ billion to establish public prescription drug coverage for every Canadian citizen and permanent resident starting in 2022. They would also "develop a roadmap" for expanding Medicare to cover universal dental care.

Otherwise, the NDP promises to work with the provinces to tackle wait times, develop public infrastructure for secure, accessible virtual health care, and create a $\$ 250$ million fund to help train and hire 2000 nurses.

The Green Party would likewise expand Medicare to include pharmacare and basic dental care among publicly insured services. The party would also establish a Crown corporation to bulk purchase drugs.

The Conservatives' platform makes no mention of pharmacare or access to care instead, the party would invest in pharmaceutical research and development and "negotiate constructively with the industry to reduce drug prices."

The Bloc would seek to negotiate lower drug prices and ensure the federal strategy on high-cost drugs harmonizes with the Quebec strategy on rare diseases. 


\section{Emergency preparedness}

While the Liberals' health promises mostly focus on Canada's ongoing COVID-19 response, including investing $\$ 100$ million to study long COVID, the Conservatives and the NDP promise to overhaul Canada's emergency stockpile system and boost domestic production of medical supplies in preparation for future pandemics.

The Conservative's plan would include reinstating tariffs on imported personal protective equipment and adopting tracking systems to ensure stockpiles are used before expiring. They also plan to overhaul federal lab testing processes to boost rapid testing capabilities and develop a national system for sharing data on infectious diseases, immunity levels and vaccination rates with transparent reporting requirements. To bolster intensive care capacity in emergencies, the Conservatives would harmonize ICU training to ensure that credentials are transferrable across the country.

In other health infrastructure, the Conservatives would develop a national isotope strategy to maintain Canada's role as an "isotope superpower" and prepare for disruptions in supply in the wake of the closure of a reactor that once produced more than 40\% of the world's medical isotopes.

And while the Conservatives promise to undo a Harper-era reorganization of PHAC that promoted a nonphysician president over the chief public health officer of Canada, the NDP will enshrine the independence of Canada's top doctor in legislation and require them to report annually to Parliament about ways to improve public health emergency preparedness.

Like the Conservatives, the NDP plans to maintain adequate stockpiles of personal protective equipment and restore a national public health surveillance system. The NDP would also establish a Crown corporation charged with domestic vaccine production and regulate natural health products under stand-alone legislation.

Bloc Québécois Leader Yves-Francois Blanchet would propose a strategy for "selfreliant" vaccine production and ensure a percentage of personal protective equipment is manufactured domestically. The Bloc would also launch an inquest into the federal government's handling of the pandemic.
The federal role in health

Under the heading of "strengthening Health Canada," the Conservative platform proposes to partner with the private sector "rather than over-rely on government," noting that some things are "best done by the private sector." The platform doesn't detail what this means.

On the campaign trail, O'Toole explained that he would like to see more private sector innovation in health care but supports "the system we have."

The Conservatives propose to strike a new health agreement with the provinces and territories to boost the annual growth rate of the Canada Health Transfer to at least 6\%. O'Toole said he wouldn't stand in the way of provinces working with the private sector to deliver care, noting his belief that private, for-profit services could help alleviate pressure on publicly run facilities.

Both the Liberals and NDP decried this stance as undercutting Canada's publicly funded health system. While the Liberals committed to strengthening federal powers to penalize provinces that allow extra billing for publicly insured services, the NDP promised to enforce the Canada Health Act, "especially against the creeping threat of privatization and user fees."

Meanwhile, the Bloc would increase federal health transfers to the provinces and territories to cover at least $35 \%$ of all health care spending.

\section{Long-term care and home care}

The Liberals, NDP and Greens have all called for national standards for long-term care to address appalling conditions exposed by the pandemic.

The Liberals would also give the provinces and territories $\$ 3$ billion to improve quality and capacity in the sector and double a home accessibility tax credit for people with disabilities to $\$ 1500$. To address staffing shortages in long-term care, the Liberals would invest $\$ 500$ million to train up to 50000 new personal support workers and guarantee them a minimum wage of $\$ 25$ perhour.

The NDP's platform includes ending private, for-profit long-term care and determining a core basket of home care services that would be covered by provincial insurance plans.
The Conservatives would amend Canada's Criminal Code to underscore facility operators' legal duty to "provide the necessities of life." To encourage Canadians to keep seniors at home, the party would provide $\$ 200$ per month to those caring for a parent over age 70. While the Conservatives would also work with provinces to develop a set of "best practices" for long-term care, it would be up to provinces to enshrine those guidelines in law.

\section{Mental health}

Most of the parties give heavy emphasis to mental health and addictions in their platforms.

The Liberals would establish a new mental health funding transfer to provinces and territories to expand the delivery of free mental health services with an initial investment of $\$ 4.5$ billion over five years. They would also review access to federal benefits for people with mental illness, include mental health as an element of occupational safety under the Canada Labour Code, and fund the hiring of up to 1200 mental health counsellors at postsecondary institutions

The Conservatives' plan includes asking the provinces to dedicate a "significant portion" of federal health funding to mental health care and encouraging employers to add mental health coverage to employee benefits by offering a $25 \%$ tax credit for the additional coverage for the first three years. They would also provide $\$ 150$ million over three years in grants to nonprofits and charities delivering mental health programming. And they would reverse a recent expansion of medical aid in dying to people with mental illness.

In response to high suicide rates among Indigenous people, the Conservatives would provide $\$ 1$ billion over five years to boost funding for Indigenous mental health and drug treatment programs. Meanwhile, the Liberals are committing a total investment of $\$ 2$ billion over five years for culturally appropriate, traumainformed supports for First Nations, Inuit and Métis people.

The NDP would "bring in mental health care for uninsured Canadians" and develop a perinatal mental health strategy. They would also create a suicide prevention action plan backed by dedicated federal resources. 


\section{Substance abuse}

Federal parties also promised measures to support Canadians with addiction.

The Liberals would develop a strategy to address problematic substance use, invest $\$ 500$ million to support the provinces and territories in providing access to treatment, and dedicate $\$ 25$ million for public education to reduce stigma. They promise to expand access to mental health courts and reform the Criminal Code to divert lower-risk and first-time offenders out of the criminal justice system.

The Conservatives would invest $\$ 325$ million over the next three years to create 1000 residential treatment beds and build 50 recovery community centres across the country. They would partner with the provinces to ensure naloxone kits are available for free across Canada. And they would revise federal drugs and substance abuse policies to focus on recovery and harm reduction.

The NDP would declare the opioid crisis a public health emergency, work with the provinces to create a safe supply of alternatives to street drugs, support overdose prevention sites and expand access to treatment on demand. They would also investigate the role drug companies played in the opioid crisis and seek financial compensation for public costs.
Finally, the Green Party would create a national drug reduction strategy, develop more safe injection sites, fund communitybased substance abuse prevention and rehab programs, and monitor opioid prescribing.

\section{Lauren Vogel and Diana Duong, CMAJ}

Content licence: This is an Open Access article distributed in accordance with the terms of the Creative Commons Attribution (CC BY-NC-ND 4.0) licence, which permits use, distribution and reproduction in any medium, provided that the original publication is properly cited, the use is noncommercial (i.e., research or educational use), and no modifications or adaptations are made. See: https://creativecommons.org/ licenses/by-nc-nd/4.0/ 